Article

\title{
Synthesis and characterization of sulfur-titanium dioxide nanocomposites for photocatalytic oxidation of cyanide using visible light irradiation
}

\author{
E. S. Baeissa* \\ Chemistry Department, Faculty of Science, King Abdulaziz University, P.O. Box 80203 Jeddah 21589, Saudi Arabia
}

\section{A R T I C L E I N F O}

Article history:

Received 1 February 2015

Accepted 27 February 2015

Published 20 May 2015

\section{Keywords:}

Titanium dioxide

Sulfur-doping

Photocatalyst

Cyanide oxidation

\begin{abstract}
A B S T R A C T
A sol-gel method was used to prepare $\mathrm{TiO}_{2}$ and sulfur- $\mathrm{TiO}_{2}\left(\mathrm{~S}-\mathrm{TiO}_{2}\right)$ nanocomposites, which were characterized by $\mathrm{N}_{2}$ adsorption-desorption, X-ray diffraction, X-ray photoelectron spectroscopy, photoluminescene, ultraviolet visible and transmission electron microscopy measurements. The photocatalytic performance of $\mathrm{TiO}_{2}$ and $\mathrm{S}_{-} \mathrm{TiO}_{2}$ nanocomposites, with respect to the photocatalytic oxidation of cyanide under visible light irradiation, was determined. The results reveal that $S$ is well dispersed on the surface of $\mathrm{TiO}_{2}$ nanoparticles. Additionally, the surface area of the $\mathrm{S}-\mathrm{TiO}_{2}$ nanocomposites was observed to be smaller than that of the $\mathrm{TiO}_{2}$ nanoparticles because of blocked pores caused by doping with $\mathrm{S}$. The $\mathrm{S}-\mathrm{TiO}_{2}$ nanocomposite $(0.3 \mathrm{wt} \% \mathrm{~S})$ exhibited the lowest band gap and the highest photocatalytic activity in the oxidation of cyanide. The photocatalytic performance of $\mathrm{S}^{-\mathrm{TiO}_{2}}(0.3 \mathrm{wt} \% \mathrm{~S})$ nanocomposites was stable, even after the fifth reuse of the nanoparticles for the oxidation of cyanide.
\end{abstract}

(C) 2015, Dalian Institute of Chemical Physics, Chinese Academy of Sciences. Published by Elsevier B.V. All rights reserved.

\section{Introduction}

Cyanide (CN) is an inorganic pollutant that is released in the aquatic environment from different anthropogenic sources. It is produced from different industries including photography, pharmaceuticals, plastics, ore leaching, metal mining, finishing, cleaning, plating, processing, electroplating, automobile parts manufacture, steel mills, steel tempering, and coal coking [1-4]. Cyanide usually exists in the form of a simple salt (KCN or $\mathrm{NaCN}$ and $\mathrm{HCN}$ ) or as part of a complex [2-8]. In soils, cyanides bond weakly to form complexes with metals found in industrial effluents, such as copper, iron, zinc and nickel. Cyanides such as the cyanide anion and hydrogen cyanide are considered the most toxic. Cyanide can also form a weak-acid dissociable complex with copper, iron, zinc and nickel $[6,7]$ and strong-acid dissociable complexes with gold, cobalt, silver and iron [6,7].
Organic cyanides such as propinonitrile and acrylonitrile also exist [9]. The concentration of cyanide in environment depends mainly on human activity. Normal cyanide levels in unpolluted stream and lake water is between 0.001-0.05 ppm [10]. The cyanide concentration range for industrial effluents is between 0.01-10.00 ppm [10]; however, levels from effluents of electroplating plants can be as high as 100,000 ppm [10]. It is therefore very important that effluents from different industries are treated to reduce the cyanide concentration level before release into the environment and a maximum concentration for levels in aquatic-biota and drinking water, respectively, were imposed by the US Environmental Protection Agency. In Germany and Switzerland, limits were set at $0.01 \mathrm{ppm}$ for surface water cyanide and $0.5 \mathrm{ppm}$ for sewers [11]. Accordingly, removal, degradation and/or recycling are crucial for reducing the cyanide concentration in different aquatic environments to

\footnotetext{
* Corresponding author. Tel: +966-26400000; Fax: +966-2-6952292; E-mail: elhambaeissa@gmail.com 
meet regulatory limits. Different methods are known for treating cyanide such as physical, adsorption, complexation, and oxidation [12-14]. Alkaline chlorination is the most common technique for removal of cyanide and increases the total solids dissolved in water [15]. Another method is the photocatalytic degradation of pollutants using solar light, which is an abundant resource, making the process more economic. [16]. The most well-known photocatalyst is $\mathrm{TiO}_{2}[17-21]$ - as a non-toxic catalyst, it can be used many times without reduction of the photocatalytic activity. The application of $\mathrm{TiO}_{2}$ particles for the photocatalytic degradation of dyes under ultraviolet (UV) or visible light has attracted much attention, compared with other less efficient conventional treatment methods $[19,20]$. Nevertheless, the application of $\mathrm{TiO}_{2}$ as a photocatalyst for wastewater treatment is relatively low because of its poor photodegradation efficiency [22]. Researchers have attempted to enhance this by the deposition and doping of metals [23-27], with mixed results [28]. The addition of adsorbent materials such as zeolites, clay, silica, alumina fiber and glass also was found to improve $\mathrm{TiO}_{2}$ photocatalytic activity [29-34]. Many recent studies showed that activated carbons could be used as a co-adsorbent and enhance $\mathrm{TiO}_{2}$ photocatalytic activity because of their high adsorption capacity and very porous structure [30-35].

It has been proposed that $\mathrm{TiO}_{2}$ photocatalytic activity initiates free radicals such as HO to degrade organic compounds [36]. Another suggested mechanism is that organic compounds are first adsorbed on the surface of the photocatalyst and then react with excited superficial $\mathrm{e}^{-} / \mathrm{h}^{+}$pairs or $\mathrm{HO} \bullet$ radicals [37]. There are few reports on the adsorption kinetics of organic compounds on photocatalysts [38-40].

Carbon nanotubes (CNTs) have attracted the attention of scientists worldwide because of the special structure of CNTs, and their electronic and mechanical properties, which has allowed them to be used for different applications. Many advanced composites are made of CNTs because of their high mechanical strength [41]. CNTs can be metallic, semi-metallic or semi-conducting, depending on their tube diameter and helicity [42], which has allowed them to be used in nanoscale electro-device applications. Their hollow and layered structures, as well as large specific surface area, have meant they have been applied in the storage of hydrogen [43] and as an adsorbent for different pollutants [44-51]. Consequently, CNTs were considered as promising materials for environmental cleaning. Progress in CNT preparation technology has seen their price decrease significantly and it is now possible to use CNTs in a large-scale operation. CNTs have two distinguishing properties that could be employed in the photodegradation of different pollutants: high adsorption capacity and excellent conductivity. The anatase form of $\mathrm{TiO}_{2}$ has superior photocatalytic activity in comparison with other photocatalysts. Therefore, the application of CNTs to the photocatalytic degradation of a dye with $\mathrm{TiO}_{2}$ as a photocatalyst is a promising strategy. Jo et al. [52] prepared aluminum sheet-based, S-doped $\mathrm{TiO}_{2}$ for the degradation of different toxic organic vapors under visible light. Mohamed et al. [53] prepared $\mathrm{P}_{-} \mathrm{TiO}_{2}$ thin films for photocatalytic degradation of butyl benzyl phthalate under visi- ble-light irradiation. Lü et al. [54] prepared $\mathrm{N}$ and $\mathrm{S}$ co-doped- $\mathrm{TiO}_{2} /$ fly ash bead composite materials for photocatalytic degradation of methylene blue dye under visible light irradiation. To the best of our knowledge, there are no reports on the oxidation of cyanide in aqueous solution by $\mathrm{S}-\mathrm{TiO}_{2}$. The present study reports the synthesis and characterization of $\mathrm{S}-\mathrm{TiO}_{2}$ nanocomposites and the evaluation of its photocatalytic activity for the oxidation of cyanide in the aqueous phase.

\section{Experimental}

All chemicals used in this study were used as received, without any further purification.

\subsection{Preparation of the photocatalyst}

The photocatalyst, $\mathrm{TiO}_{2}$, was prepared by the following method: $0.04 \mathrm{~g}$ of $36 \% \mathrm{HCl}$ was dissolved in $10 \mathrm{~mL}$ of water and then added dropwise to dodecylamine solution (3 $\mathrm{g}$ in 30 $\mathrm{mL}$ water). The resulting solution A was stirred at room temperature for $1 \mathrm{~h}$; $0.8 \mathrm{~g}$ of titanium isopropoxide dissolve in 18 $\mathrm{mL}$ of isopropyl alcohol and the resulting solution B was stirred at room temperature for $1 \mathrm{~h}$. Solution A was added to solution $\mathrm{B}$ and stirred at room temperature for $24 \mathrm{~h}$, followed by filtration and calcination for $5 \mathrm{~h}$ at $550{ }^{\circ} \mathrm{C}$. S- $\mathrm{TiO}_{2}$ samples (containing $0.1 \mathrm{wt} \%, 0.2 \mathrm{wt} \%, 0.3 \mathrm{wt} \%$ and $0.4 \mathrm{wt} \%$ of S) were synthesized using the same method of preparation of $\mathrm{TiO}_{2}$; however, titanium isopropoxide was mixed with thiourea as the source of sulfur.

\subsection{Characterization techniques}

X-ray diffraction (XRD) analysis was performed at room temperature with a Bruker axis D8 using $\mathrm{Cu}-K_{\alpha}$ radiation $(\lambda=$ $0.154 \mathrm{~nm}$ ). The specific surface area was calculated from $\mathrm{N}_{2}$-adsorption measurements, which were obtained using a Nova 2000 series Chromatech apparatus at $-196{ }^{\circ} \mathrm{C}$. Prior to the measurements, the samples were treated under vacuum at $100{ }^{\circ} \mathrm{C}$ for $2 \mathrm{~h}$. The band gap of the samples was identified by UV-visible diffuse reflectance spectroscopy (UV-Vis-DRS), which was performed in air, at room temperature over the wavelength range of 200-800 nm using a UV/Vis/NIR spectrophotometer (V-570, JASCO, Japan). Transmission electron microscope (TEM) analysis was conducted with a JEOL-JEM-1230 microscope, and samples were prepared by suspension in ethanol, followed by ultrasonication for $30 \mathrm{~min}$. Subsequently, a small amount of this solution was placed onto a carbon-coated copper grid and dried before loading the sample into the TEM. X-ray photoelectron spectroscopy (XPS) studies were performed using a Thermo Scientific K-ALPHA, XPS, England. Photoluminescence (PL) emission spectra were recorded using a Shimadzu RF-5301 fluorescence spectrophotometer. The actual amount of sulfur in prepared samples was ascertained by inductively coupled plasma-mass spectrometry (ICP-MS). It was found that $0.1 \mathrm{wt} \%, 0.2 \mathrm{wt} \%, 0.3 \mathrm{wt} \%$ and 0.4 wt $\% \mathrm{~S}-\mathrm{TiO}_{2}$ comprised of $0.95 \mathrm{wt} \%, 0.20 \mathrm{wt} \%, 0.30 \mathrm{wt} \%$ and 0.39 wt $\%$ S, respectively. 


\subsection{Analysis of hydroxyl radicals}

The formed hydroxyl radical $(\cdot \mathrm{OH})$ on the surface was measured by a photoluminescence method $[55,56]$, which uses terephthalic acid as a probe molecule. The intensity of the PL signal of 2-hydroxyterephthalic acid, produced by the reaction of terephthalic acid with $\cdot \mathrm{OH}$, was measured at $425 \mathrm{~nm}$. Therefore, the amount of $\bullet \mathrm{OH}$ produced on the surface of $\mathrm{TiO}_{2}$ is proportional to the PL intensity of 2-hydroxy terephthalic acid. To measure $\cdot \mathrm{OH}$ radicals, $0.1 \mathrm{~g}$ of the prepared sample was dispersed in a terephthalic acid aqueous solution $\left(20 \mathrm{~mL}, 5 \times 10^{-4}\right.$ $\mathrm{mol} / \mathrm{L})$ with $\mathrm{NaOH}\left(2 \times 10^{-3} \mathrm{~mol} / \mathrm{L}\right)$ in a dish with a diameter of approximately $9.0 \mathrm{~cm}$. The light source was a $125 \mathrm{~W}$ high pressure Hg lamp, held $10 \mathrm{~cm}$ above the dishes. The integrated visible light intensity measured with a visible light radiometer (Model: FZ-A) was $2.9 \mathrm{~mW} / \mathrm{cm}^{2}$, and the wavelength range was 400-1000 nm. Photoluminescence spectra of the generated 2-hydroxyterephthalic acid were measured on a Shimadzu RF-5301 fluorescence spectrophotometer. After irradiation every $10 \mathrm{~min}$, the reaction solution was filtered to measure the increase in the PL intensity at $425 \mathrm{~nm}$.

\subsection{Photocatalysis experiment}

The application of synthesized nanocomposites for the photodegradation of cyanide was investigated under visible light. The experiments were carried out using a horizontal cylinder annular batch reactor. The photocatalyst was irradiated with a blue fluorescent lamp $(150 \mathrm{~W})$ and the reactor doubly covered with a UV cut filter. In a typical experiment, photocatalyst was added to a $300-\mathrm{mL}, 100-\mathrm{mg} / \mathrm{L}$ potassium cyanide (KCN) solution ( $\mathrm{pH} 10.5$, which was adjusted by ammonia solution to avoid the evolution of HCN gas). The reaction was carried out isothermally at $25{ }^{\circ} \mathrm{C}$ and samples of the reaction mixture were taken at different intervals for a total reaction time of $1 \mathrm{~h}$. The $\mathrm{CN}^{-}$(aq) concentration in the samples was estimated by volumetric titration with silver nitrate, using potassium iodide to determine the titration end point. The removal efficiency of $\mathrm{CN}^{-}$(aq) has been measured by applying the following

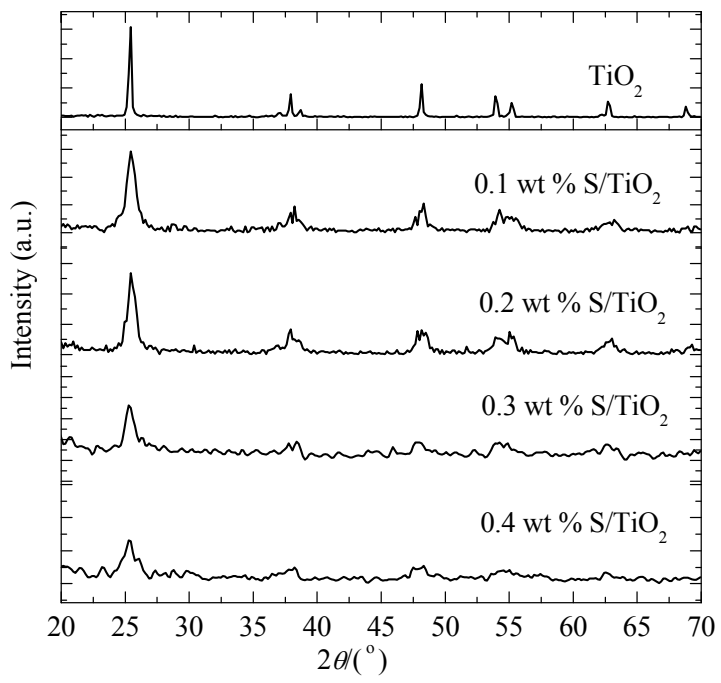

Fig. 1. XRD patterns of $\mathrm{TiO}_{2}$ and $\mathrm{S}-\mathrm{TiO}_{2}$ nanocomposites.

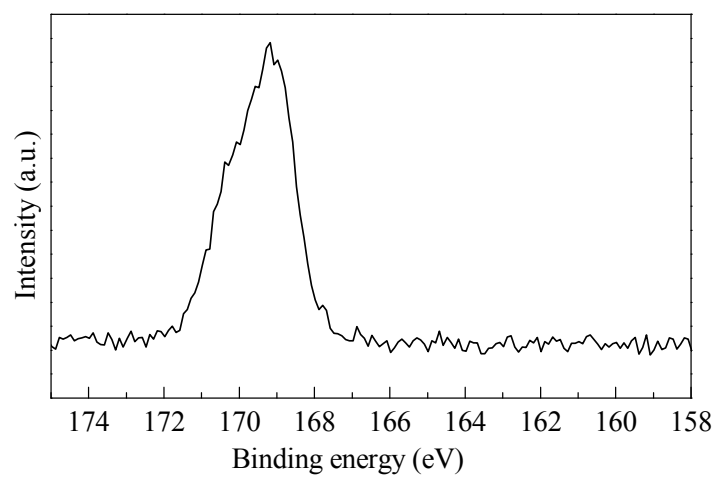

Fig. 2. XPS spectrum of $\mathrm{S} 2 p\left(0.3 \mathrm{wt} \% \mathrm{~S}-\mathrm{TiO}_{2}\right.$ sample).

equation

Removal efficiency $(\%)=\left(C_{0}-C\right) / C_{0} \times 100$

Where $C_{0}$ is the initial concentration of uncomplexed $\mathrm{CN}^{-}$(aq) in solution, $C$ is the concentration of unoxidized $\mathrm{CN}^{-}$(aq) in solution.

\section{Results and discussion}

\subsection{Structural, morphological and compositional characterizations}

Figure 1 shows the XRD patterns of the $\mathrm{TiO}_{2}$ and $\mathrm{S}-\mathrm{TiO}_{2}$ nanocomposites. The results show that the nanocomposites are mainly composed of $\mathrm{TiO}_{2}$ anatase and indicate a lack of diffraction peaks from $\mathrm{S}$ or $\mathrm{SO}_{2}$ in the patterns of the $\mathrm{S}^{-\mathrm{TiO}_{2}}$ samples. This is because the wt\% of $\mathrm{S}$ is below the XRD detection limit, or perhaps because $\mathrm{S}$ is well dispersed on surface of the $\mathrm{TiO}_{2}$ nanoparticles.

Figure 2 shows the XPS spectrum of $S 2 p$ for a sample of $\mathrm{S}-\mathrm{TiO}_{2}$. The peak for S $2 p$ at $169.2 \mathrm{eV}$ confirms the presence of $\mathrm{S}$ in the sample.

Figure 3 shows TEM images of $\mathrm{S}^{-\mathrm{TiO}_{2}}$ nanocomposites. The

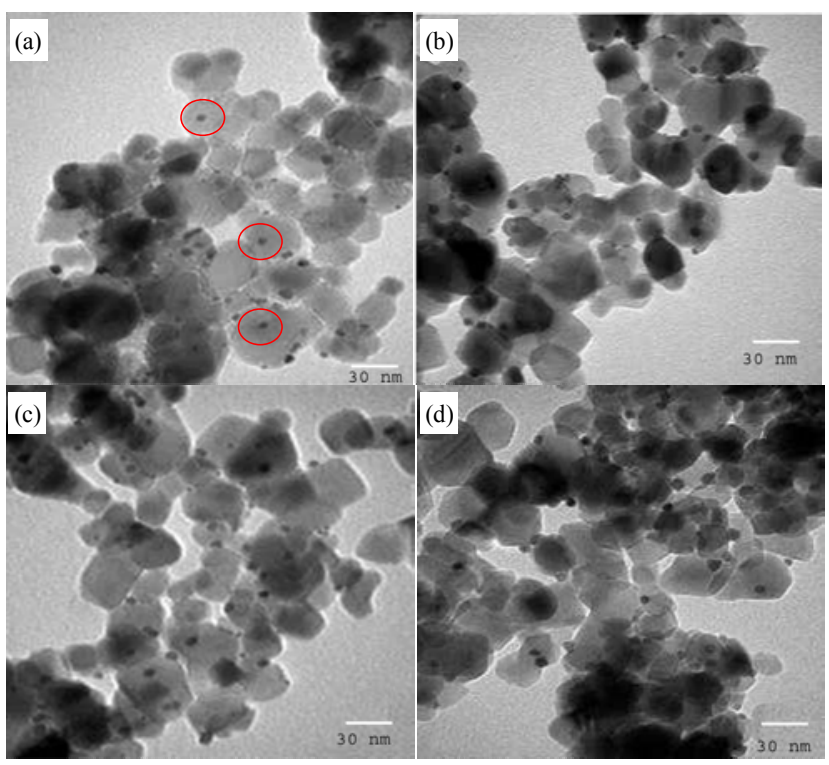

Fig. 3. TEM images of $\mathrm{S}^{-\mathrm{TiO}_{2}}$ nanocomposites, where the wt $\%$ of $\mathrm{S}$ is 0.1 (a), 0.2 (b), 0.3 (c), 0.4 (d). 
Table 1

Textural parameters of $\mathrm{TiO}_{2}$ and $\mathrm{S}^{-\mathrm{TiO}_{2}}$ nanocomposites.

\begin{tabular}{|c|c|c|c|c|c|c|c|c|}
\hline Sample & $S_{\mathrm{BET}}\left(\mathrm{m}^{2} / \mathrm{g}\right)$ & $S_{\mathrm{t}}\left(\mathrm{m}^{2} / \mathrm{g}\right)$ & $S_{\text {micro }}\left(\mathrm{cm}^{2} / \mathrm{g}\right)$ & $S_{\text {ext }}\left(\mathrm{cm}^{2} / \mathrm{g}\right)$ & $V_{\mathrm{p}}\left(\mathrm{cm}^{3} / \mathrm{g}\right)$ & $V_{\text {micro }}\left(\mathrm{cm}^{3} / \mathrm{g}\right)$ & $V_{\text {meso }}\left(\mathrm{cm}^{3} / \mathrm{g}\right)$ & $r(\mathrm{~nm})$ \\
\hline$\overline{\mathrm{TiO}_{2}}$ & 56.00 & 56.00 & 36.00 & 23.00 & 0.220 & 0.174 & 0.060 & 3.5 \\
\hline $0.1 \mathrm{wt} \% \mathrm{~S}-\mathrm{TiO}_{2}$ & 53.00 & 53.00 & 34.00 & 19.00 & 0.165 & 0.130 & 0.035 & 4.5 \\
\hline $0.2 \mathrm{wt} \% \mathrm{~S}-\mathrm{TiO}_{2}$ & 51.00 & 52.00 & 33.00 & 18.00 & 0.142 & 0.110 & 0.032 & 5.5 \\
\hline $0.3 w \mathrm{t} \% \mathrm{~S}-\mathrm{TiO}_{2}$ & 49.00 & 49.00 & 32.00 & 18.00 & 0.135 & 0.105 & 0.030 & 6.0 \\
\hline $0.4 \mathrm{wt} \% \mathrm{~S}-\mathrm{TiO}_{2}$ & 44.00 & 44.00 & 25.00 & 16.00 & 0.120 & 0.095 & 0.020 & 6.5 \\
\hline
\end{tabular}

Note: $S_{\mathrm{BET}}-\mathrm{BET}$-surface area, $S_{\mathrm{t}}-$ surface area derived from $V_{\mathrm{l}-\mathrm{t}}$ plots, $S_{\text {micro }}-$ surface area of micropores, $S_{\text {ext }}$-external surface area, $V_{\mathrm{p}}-$ total pore volume, $V_{\text {micro }}$-volume of micropores, $V_{\text {meso }}$-volume of mesopores, $r$-mean pore radius.

results show that an increase in $\mathrm{S}$ content increases the dispersion of $\mathrm{S}$ on the surface of the $\mathrm{TiO}_{2}$ nanoparticles. Additionally, an increase of up to $0.3 \% \mathrm{~S}$ increases the homogeneity of the S particle size on the $\mathrm{TiO}_{2}$ nanoparticle surface. This homogeneity decreases at higher concentrations i.e., $0.4 \mathrm{wt} \% \mathrm{~S}$, which suggests that there is an optimum content of $\mathrm{S}$ ions that controls the size and homogeneity.

\subsection{Surface area analysis}

The texture parameters of the $\mathrm{TiO}_{2}$ and $\mathrm{S}-\mathrm{TiO}_{2}$ nanocompo-

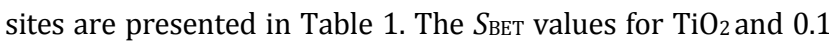
$w \mathrm{t} \%, 0.2 \mathrm{wt} \%, 0.3 \mathrm{wt} \%$, and $0.4 \mathrm{wt} \% \mathrm{~S}-\mathrm{TiO}_{2}$ were determined to be $56,53,51,49$, and $44 \mathrm{~m}^{2} / \mathrm{g}$, respectively. The total pore volume of $\mathrm{S}-\mathrm{TiO}_{2}$ samples is smaller than that of the $\mathrm{TiO}_{2}$ sample because of the blocking of some pores by deposition of sulfur. The presence of mesopores in all samples was confirmed by the similar values of $S_{\mathrm{BET}}$ and $S_{\mathrm{t}}$ in most samples, as presented in Table 1.

\subsection{Optical characterization}

Figure 4 shows the UV-Vis diffuse reflectance spectra of $\mathrm{TiO}_{2}$ and $\mathrm{S}-\mathrm{TiO}_{2}$ nanocomposites. The results demonstrate that the doping of sulfur onto the surface of $\mathrm{TiO}_{2}$ leads to a shift in the absorption edge of $\mathrm{TiO}_{2}$ from 394 to $455 \mathrm{~nm}$. The UV-Vis spectra were used to calculate the direct band gap of the $\mathrm{TiO}_{2}$ and $\mathrm{S}-\mathrm{TiO}_{2}$ nanocomposites based on a method by Mohamed [29]. The band gap energies were calculated using the following equation:

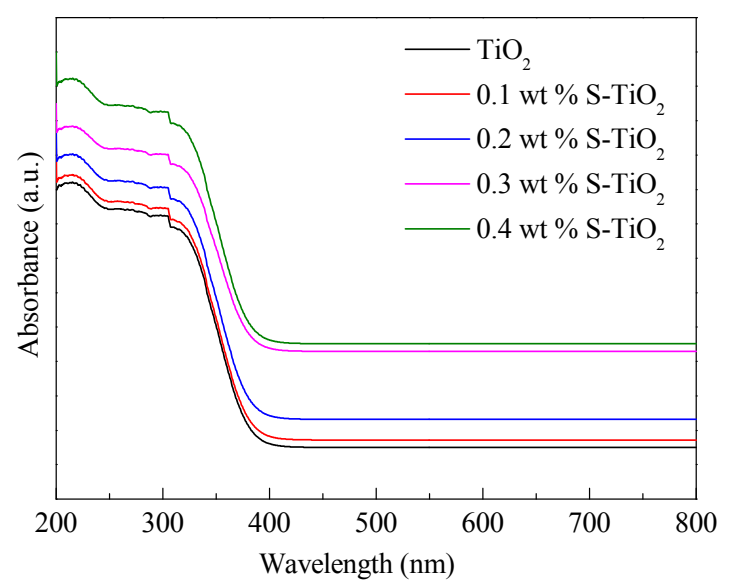

Fig. 4. UV-Vis absorption spectra of $\mathrm{TiO}_{2}$ and $\mathrm{S}-\mathrm{TiO}_{2}$ nanocomposites.

$$
E_{\mathrm{g}}=1239.8 / \lambda
$$

Where $E_{g}$ is the band gap (eV) and $\lambda$ is the wavelength $(\mathrm{nm})$ of the absorption edges in the spectrum (Table 2). The results reveal that an increase in sulfur from $0.1 \mathrm{wt} \%$ to $0.3 \mathrm{wt} \%$ decreases the band gap energy from 3.15 to $2.75 \mathrm{eV}$. However, there is no significant effect on the band gap at a content of $\mathrm{S}$ greater than 0.3 . Therefore, there is an optimum content of deposited $\mathrm{S}$ that controls the band gap.

We investigated the separation and recombination of photogenerated charge carriers and the transfer of the photogenerated electrons and holes by gathering photoluminescence emission spectra. Figure 5 shows (PL) spectra of $\mathrm{TiO}_{2}$ and $\mathrm{S}-\mathrm{TiO}_{2}$ nanocomposites. The results indicate that an increase in S content from $0.1 \mathrm{wt} \%$ to $0.3 \mathrm{wt} \%$, which was doped onto the $\mathrm{TiO}_{2}$ nanoparticles, leads to a decrease in the PL intensity. However, there is no significant effect on the PL intensity at a content of sulfur above $0.3 \mathrm{wt} \%$. Therefore, there is an optimum content of deposited $\mathrm{S}$ that yields the carrier lifetime required for electron-hole recombination, in agreement with the UV-Vis results.

Table 2

Band gap energy of $\mathrm{TiO}_{2}$ and $\mathrm{S}-\mathrm{TiO}_{2}$ nanocomposites.

\begin{tabular}{lc}
\hline Sample & Band gap energy $(\mathrm{eV})$ \\
\hline $\mathrm{TiO}_{2}$ & 3.15 \\
$0.1 \mathrm{wt} \% \mathrm{~S}-\mathrm{TiO}_{2}$ & 3.05 \\
$0.2 \mathrm{wt} \% \mathrm{~S}-\mathrm{TiO}_{2}$ & 2.91 \\
$0.3 \mathrm{wt} \% \mathrm{~S}-\mathrm{TiO}_{2}$ & 2.75 \\
$0.4 \mathrm{wt} \% \mathrm{~S}-\mathrm{TiO}_{2}$ & 2.74 \\
\hline
\end{tabular}

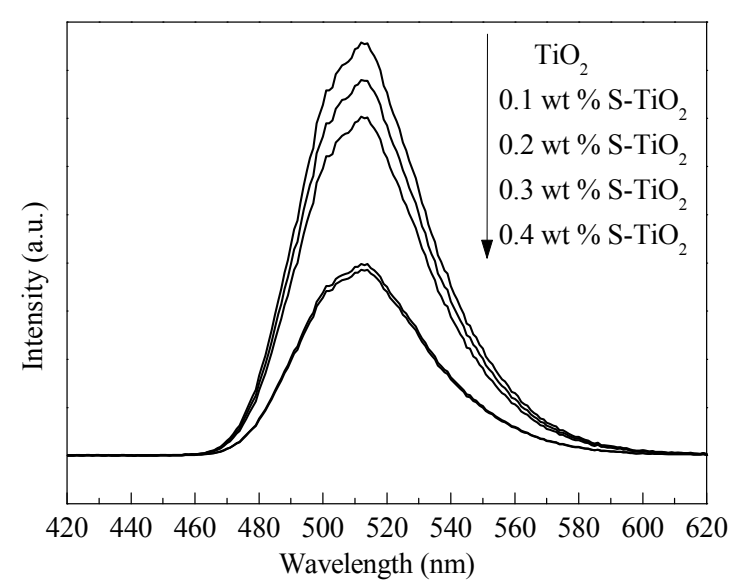

Fig. 5. PL spectra of $\mathrm{TiO}_{2}$ and $\mathrm{S}-\mathrm{TiO}_{2}$ nanocomposites. 


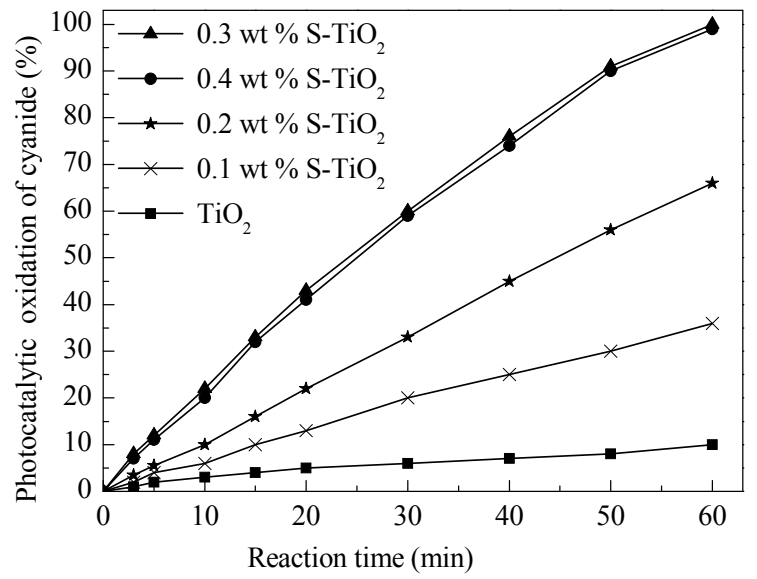

Fig. 6. Effect of the content of $\mathrm{S}$ on the photocatalytic activity of $\mathrm{TiO}_{2}$ nanocomposites for the oxidation of cyanide.

\subsection{Photocatalytic activity}

Figure 6 shows the effect of changing the content of $S$ on the photocatalytic activity of $\mathrm{TiO}_{2}$ nanoparticles on the oxidation of cyanide under visible light irradiation. The experiment was performed under the following conditions: KCN (100 ppm, 500 $\mathrm{mL}$ ) and $0.2 \mathrm{~g}$ photocatalyst. The results reveal that the photocatalytic activity increased from $10 \%$ to $100 \%$, with an increase in sulfur from 0 to $0.3 \mathrm{wt} \%$. However, increasing sulfur above $0.3 \mathrm{wt} \%$ led to a decrease in the photocatalytic activity from $100 \%$ to $99 \%$. This decrease was observed because a high content of sulfur hinders the penetration of light to the surface of $\mathrm{TiO}_{2}$, thereby decreasing the photocatalytic performance of $\mathrm{TiO}_{2}$, with respect to the oxidation of cyanide.

The change in PL spectra with increased irradiation time for the $0.3 \mathrm{wt} \% \mathrm{~S}-\mathrm{TiO}_{2}$ sample in a terephthalic acid solution is shown in Fig. 7(a). The results show that a gradual increase in PL intensity at $425 \mathrm{~nm}$ occurs with increasing irradiation time. No PL increase was observed in the absence of visible light or in the $0.3 \mathrm{wt} \% \mathrm{~S}^{-\mathrm{TiO}_{2}}$ sample not in a terephthalic acid solution. This suggests that the fluorescence is from the chemical reactions between terephthalic acid and $\cdot \mathrm{OH}$ formed at the $0.3 \mathrm{wt} \%$ $\mathrm{S}-\mathrm{TiO}_{2} /$ water interface via photocatalytic reactions. The change

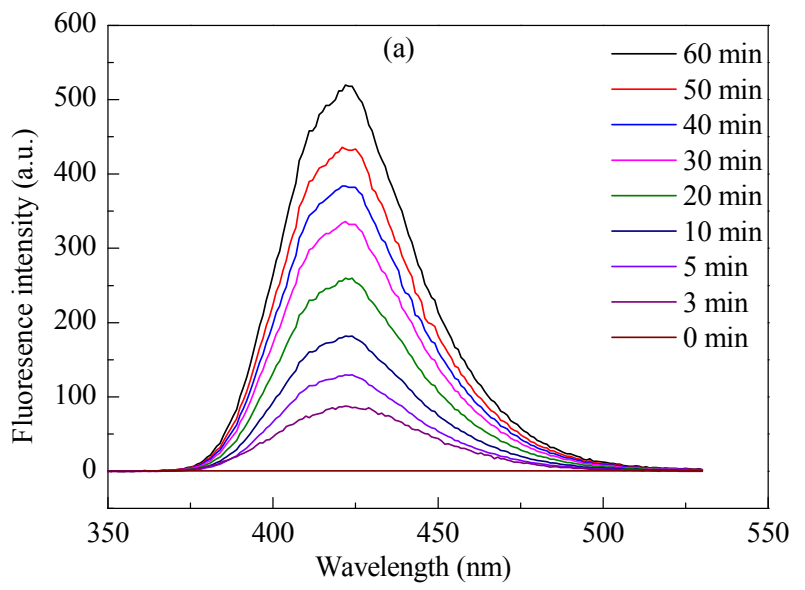

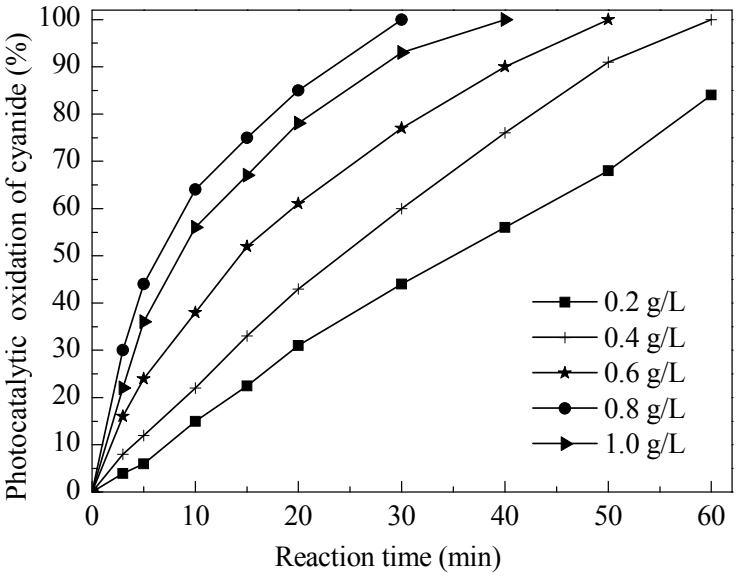

Fig. 8. Effect of loading of the 0.3 wt $\% \mathrm{~S}^{-\mathrm{TiO}_{2}}$ sample on the photocatalytic oxidation of cyanide.

in PL spectra based on irradiation time for different samples is shown in Fig. 7(b). The results show that $\cdot \mathrm{OH}$ is produced from 0.3 wt $\% \mathrm{~S}^{-\mathrm{TiO}_{2}}$ nanoparticles more quickly than on the undoped $\mathrm{TiO}_{2}, 0.1 \mathrm{wt} \%, 0.2 \mathrm{wt} \%$, and $0.4 \mathrm{wt} \% \mathrm{~S}-\mathrm{TiO}_{2}$ samples. Thus, the $0.3 \mathrm{wt} \% \mathrm{~S}^{-\mathrm{TiO}_{2}}$ nanoparticles the highest photocatalytic activity under visible light.

Figure 8 shows the effect of loading the $0.3 \mathrm{wt} \% \mathrm{~S}-\mathrm{TiO}_{2}$ sample on the photocatalytic oxidation of cyanide solution under visible light irradiation. The experiment was performed under the following conditions: KCN (100 ppm, $1 \mathrm{~L}$ ) and 0.3 wt $\% \mathrm{~S}-\mathrm{TiO}_{2}$ nanocomposite. The results reveal that photocatalytic performance after 60 min was increased from $82 \%$ to $100 \%$, with an increase in the weight of the photocatalyst from 0.2 to $0.4 \mathrm{~g} / \mathrm{L}$. The reaction time required to complete the oxidation of cyanide was 60,50 , and $30 \mathrm{~min}$ as the weight of the photocatalyst was increased to $0.4,0.6$, and $0.8 \mathrm{~g} / \mathrm{L}$, respectively. However, the reaction time required to complete the oxidation of cyanide was increased to $40 \mathrm{~min}$, with an increase in the weight of the photocatalyst above $0.8 \mathrm{~g} / \mathrm{L}$; i.e., the optimum weight of the photocatalyst is $0.8 \mathrm{~g} / \mathrm{L}$.

Figure 9 shows the effect on photocatalytic oxidation of cyanide solution under visible light irradiation, which was studied by varying the KCN solution concentration from 25 to $200 \mathrm{ppm}$

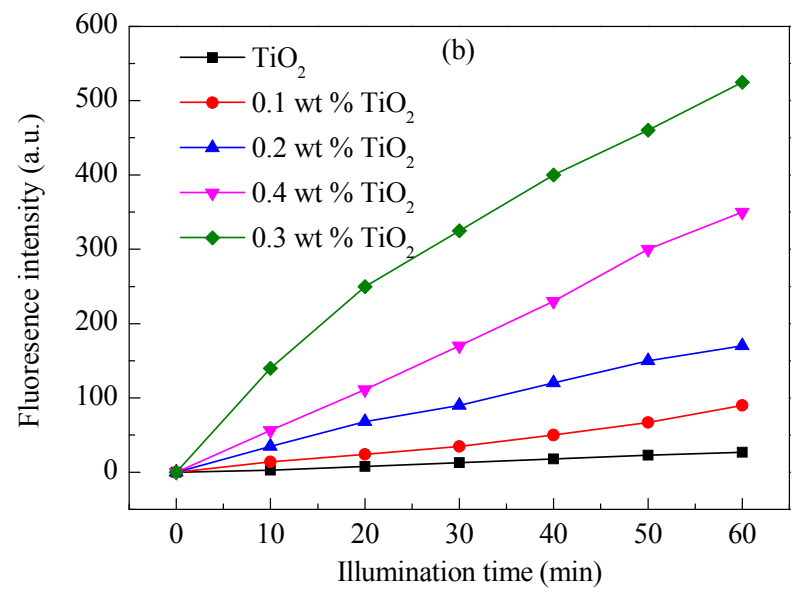

Fig. 7. Fluorescence spectral changes in a $\mathrm{NaOH}$ solution of terephthalic acid for $0.3 \mathrm{wt} \% \mathrm{~S}^{-\mathrm{TiO}_{2}}$ (a) and other catalysts (b). 


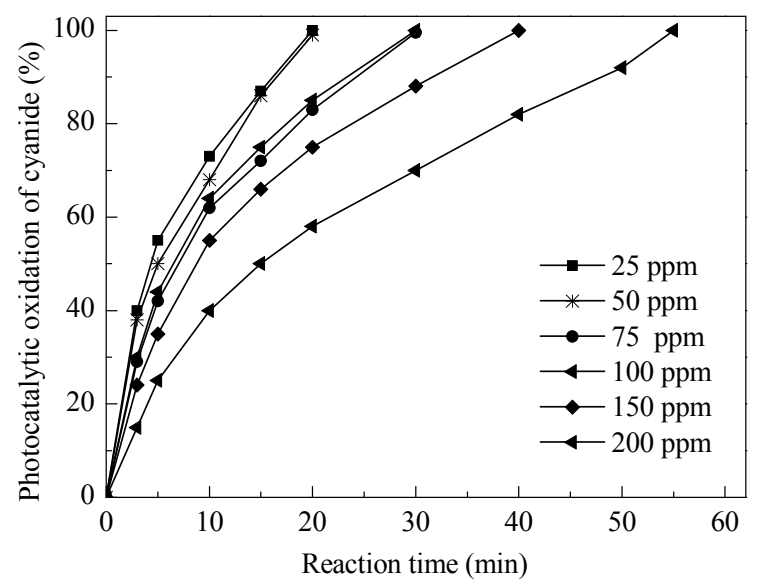

Fig. 9. Effect of the initial cyanide solution concentration on the photocatalytic oxidation of cyanide solution.

in the presence of $0.3 \mathrm{wt} \% \mathrm{~S}^{-\mathrm{TiO}_{2}}$ photocatalyst. The results demonstrate that the photocatalytic activity remained nearly unchanged with an increase in the KCN solution concentration after $30 \mathrm{~min}$ of reaction time required to complete the oxidation of cyanide. However, for cyanide solution concentrations above 100 ppm, i.e., 150 and 200 ppm, the reaction time required to complete the oxidation of cyanide was increased to 40 and $60 \mathrm{~min}$, respectively. The photocatalytic activity depends on $\cdot \mathrm{OH}$ reaching the surface of the catalyst and then reacting with the cyanide solution; therefore, increasing the concentration increases the probability of a reaction between the free radicals and the cyanide solution, thereby increasing the photocatalytic activity. A further increase in the cyanide solution concentration decreases the photocatalytic activity because the active sites of the photocatalyst are blocked by cyanide solution, preventing visible light from penetrating the surface of active sites.

Testing the photocatalyst for multiple cycles is an important factor for commercial use of the photocatalyst. Figure 10 shows the degradation of cyanide remains at $100 \%$ even after the 0.3 $\mathrm{wt} \% \mathrm{~S}^{-\mathrm{TiO}_{2}}$ photocatalyst is reused five times.

\section{Conclusions}

In summary, a $\mathrm{S}^{-} \mathrm{TiO}_{2}$ nanocomposite photocatalyst was

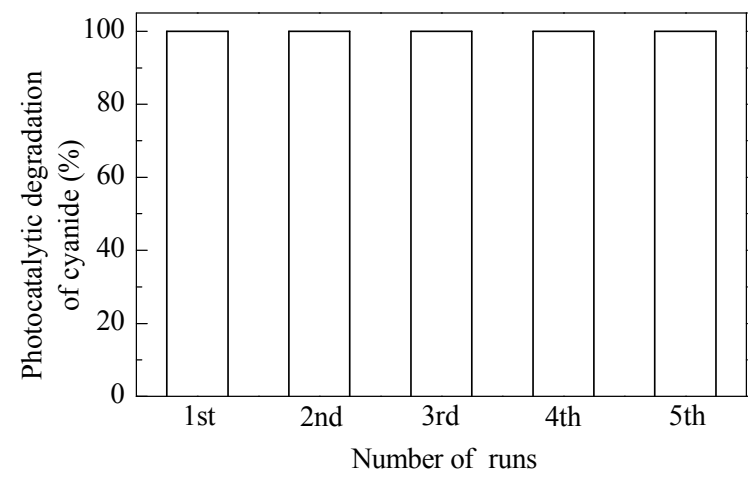

Fig. 10. Recycling and reuse of the $0.3 \mathrm{wt} \% \mathrm{~S}^{-\mathrm{TiO}_{2}}$ sample for the photocatalytic degradation of cyanide. successfully synthesized and proven to be a promising catalyst because of its high efficiency in oxidizing the pollutant cyanide under visible light. The band gap of the $\mathrm{TiO}_{2}$ photocatalyst can be controlled by adjusting the content of $\mathrm{S}$ that is deposited onto its surface. The results of photocatalytic studies reveal that the highest photocatalytic activity and stability were obtained from the $0.3 \mathrm{wt} \% \mathrm{~S}^{-} \mathrm{TiO}_{2}$ nanocomposite photocatalyst, which can be used to oxidize $100 \%$ of a cyanide solution after 30 min exposure.

\section{References}

[1] Kim Y M, Cho H U, Lee D S, Park D, Park J M. Desalination, 2011, 279: 439

[2] Yeddou A R, Chergui S, Chergui A, Halet F, Hamza A, Nadjemi B, Ould-Dris A. Belkouch J. Miner Eng, 2011, 24: 788

[3] Bhattacharya P, Ghosh S, Mukhopadhyay A. J Environ Chem Eng, 2013, 1: 38

[4] Depci T. Chem Eng J, 2012, 181-182: 467

[5] Do S H, Jo Y H, Park H D, Kong S H. Chemosphere, 2012, 89: 1450

[6] Mohamed R M. Ceram Int, 2015, 41: 1197

[7] Mohamed R M, Baeissa E S. Appl Catal A, 2013, 464-465: 218

[8] Kao C M, Chen K F, Liu J K, Chou S M, Chen S C. Appl Microbiol Biotechnol, 2006, 71: 228

[9] Dash R R, Gaur A, Balomajumder C. J Hazard Mater, 2009, 163: 1

[10] Mohamed R M, McKinney D L, Sigmund W M. Mater Sci Eng R, 2012, 73: 1

[11] Mohamed R M, Mkhalid I A. J Alloy Comp, 2010, 501: 143

[12] Mohamed R M, Mkhalid I A. J Alloy Comp, 2010, 501: 301

[13] Pak D, Chang W. Environ Technol, 1997, 18: 557

[14] Mohamed R M, Baeissa E S. J Alloy Comp, 2013, 558: 68

[15] Zagury G J, Oudjehani K, Deschenes L. Sci Total Environ, 2004, 320 : 211

[16] Sharma V K, Rivera W, Smith J O, O'Brien B. Environ Sci Technol, 1998, 32: 2608

[17] Bahnemann D. Solar Energy, 2004, 77: 445

[18] Chiang K, Amal R, Tran T. J Mol Catal A, 2003, 193: 285

[19] Liu H M, Imanishi A, Nakato Y.J Phys Chem C, 2007, 111: 8603

[20] Abdelaal M Y, Mohamed R M. J Alloy Comp, 2013, 576: 201

[21] Harraz F A, Abdel-Salam O E, Mostafa A A, Mohamed R M, Hanafy M. J Alloy Comp, 2013, 551: 1

[22] Mohamed R M. Desalination Water treatment, 2012, 50: 147

[23] Mohamed R M, Aazam E S. Appl Catal A, 2014, 480: 100

[24] Mohamed R M, Aazam E S. J Alloy Comp, 2011, 509: 101032

[25] Mohamed R M, Aazam E S. Int J Photoenergy, 2011: 137328

[26] Mohamed R M, El-Toni A M, Harraz F A, Ibrahim I A.J Envir Sci Eng, 2010, 4: 36

[27] Mohamed R M, Aazam E S. J Alloy Comp, 2014, 595: 8

[28] Mohamed R M, Aazam E S. Mater Res Bull, 2013, 48: 3572

[29] Mohamed R M, Mori K, Yamashita H. Int J Nanoparticles, 2009, 2: 512

[30] El-Bahy Z M, Ismail A A, Mohamed R M. J Hazard Mater, 2009, 166: 138

[31] Mohamed R M.J Mater Proc Tech, 2009, 209: 577

[32] Mohamed R M, Ibrahim F M, Mori K, Yamashita H. Stud Surf Sci Catal, 2008, 174: 1255

[33] Aal A A, Barakat M A, Mohamed R M. App Sur Sci, 2008, 254: 4577

[34] Mohamed R M, El-Midany A A, Othman I. Research on Chemical Intermediates, 2008, 34(5-7): 629

[35] Mohamed M M, Othman I, Mohamed R M. J Photochem Photobiol A, 2007, 191: 153 


\section{Graphical Abstract}

Chin. J. Catal., 2015, 36: 698-704 doi: 10.1016/S1872-2067(14)60320-X

\section{Synthesis and characterization of sulfur-titanium dioxide nanocomposites for photocatalytic oxidation of cyanide using visible light irradiation}

E. S. Baeissa*

King Abdulaziz University, Saudi Arabia

$\mathrm{S}-\mathrm{TiO}_{2}$ nanocomposite photocatalyst can degrade waste materials under visible light. $\mathrm{S}_{-} \mathrm{TiO}_{2}$ nanocomposite has lower band gap and higher photo catalytic activity than $\mathrm{TiO}_{2}$ nanoparticle. $\mathrm{S}-\mathrm{TiO}_{2}$ nanocomposite can be recycled for five times.

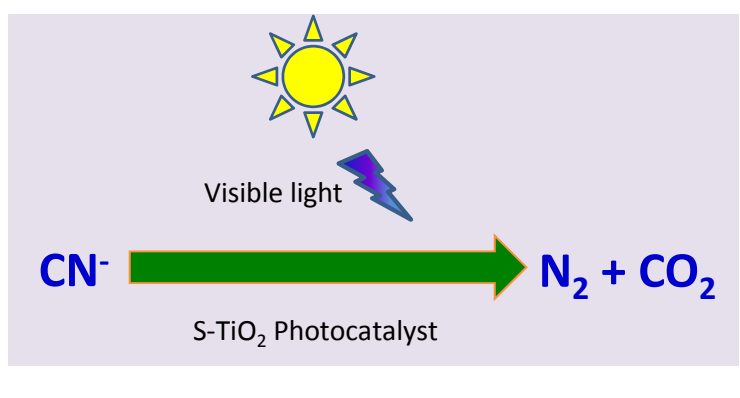

[36] Othman I, Mohamed R M, Ibrahim I A, Mohamed M M. Appl Catal A, 2006, 299: 95

[37] Arana J, Dona-Rodriguez J M, Rendon E T, Cabo C G, Gonzalez-Diaz, Herrera-Melian J A, Perez-pena J, Colon G, Navio J A. Appl Catal B, 2003, 44: 153

[38] Tryba B, Morawske A W, Inagaki M. Appl Catal B, 2003, 41: 427

[39] Matos J, Laine J, Herrmanna J M. Appl Catal B, 1998, 18: 281

[40] Han Z, Fina A. Prog Polym Sci, 2011, 36: 914

[41] Kormann C, Bahnemann D W, Hoffmann M R. Environ Sci Technol, 1991, 25: 494

[42] Oriňáková R, Oriňák A. Fuel, 2011, 90: 3123

[43] Miranda S M, Romanos G E, Likodimos V, Marques R R N, Favvas E P, Katsaros F K, Stefanopoulos K L, Vilar V J P, Faria J L, Falaras P, Silva A M T. Appl Catal B, 2014, 147: 65

[44] Dalt S D, Alves A K, Bergmann C P. Mater Res Bull, 2013, 48: 1845

[45] Liu C, Chen H, Dai K, Xue A, Chen H, Huang Q. Mater Res Bull, 2013, 48: 1499
[46] Zhu P, Nair A S, Yang S, Ramakrishna S. Mater Res Bull, 2011, 46: 588

[47] Wang W, Serp P, Kalck P, Faria J L. J Mol Catal A, 2005, 235: 194

[48] Zhou W, Pan K, Qu Y, Sun F, Tian C, Ren Z, Tian G, Fu H. Chemosphere, 2010, 81: 555

[49] Nishio J, Tokumura M, Znad HT, Kawase Y. J Hazard Mater, 2006, 138: 106

[50] Fasfous I I, Radwan E S, Dawoud J N. Appl Surf Sci, 2010, 256: 7246

[51] Li X, Zhao H, Quan X, Chen S, Zhang Y, Yu H.J Hazard Mater, 2011, 186: 407

[52] Jo W K, Kang H J. Chin J Catal (催化学报), 2014, 35: 1189

[53] Mohamed R M, Baeissa E. Chin J Catal (催化学报), 2013, 34: 1267

[54] Lü J, Sheng T, Su L, Xu G, Wang D, Zheng Z, Wu Y. Appl Sur Sci, 2013, 284: 229

[55] Rashid J, Barakat M A, Mohamed R M, Ibrahim I A.J Photochem Photobiol A, 2014, 284: 1

[56] Xiang Q, Yu J, Wong P K. J Colloid Interf Sci, 2011, 357: 163 